\title{
THE "RATCHET EFFECT" IN THE GROWTH OF GOVERNMENT: A VIABLE HYPOTHESIS FOR THE CASE OF ARGENTINA?
}

\section{Ariel R. Tejera}

National University of Rosario, Rosario, Argentina

\section{Leandro A. Veron}

National University of Rosario, Rosario, Argentina

\author{
Alan G. Futerman \\ University of the Latin American Educational Center, Rosario, Argentina \\ CMESTE \\ JEL Category: E14, $\mathrm{H1}, \mathrm{H} 5, \mathrm{E3}$
}

\begin{abstract}
The present work analyses the "Ratchet Effect" theory as developed by Robert Higgs, originally presented to explain the dynamics in the growth of government for the case of the US, to study its possible application to the case of Argentina. The theory explains that the government grows during recessionary periods and later decreases but in a lower proportion than the initial expansion. Hence, a ratchet is identified in the government growth dynamic. For this purpose, a quantitative analysis is presented based on the econometric model by Hercowitz and Strawczynski, by using the data of Public Expenditure of Argentina corresponding to the years between 1961 and 2009. Although a qualitative analysis of the kind presented by Higgs is not developed in the present work, a quantitative analysis does not corroborate the application of the theory to the case under study. Therefore, our study claims that the government growth dynamic in Argentina is different than in the US, or any other country that registers a specific government growth compatible with the "Ratchet Effect" theory. Although our analysis does not invalidate the possibility of the existence of a specific dynamic in the growth of Argentina's government compatible with Higgs' hypothesis based on qualitative data, we believe that a quantitative corroboration of the theory is relevant to identify its applicability in any given case.
\end{abstract}

Keywords: Government Growth, Ratchet Effect, Argentina, Robert Higgs, Business Cycle

\section{INTRODUCTION}

Address of the corresponding author: Alan G. Futerman

奉=1 alanfuterman@catalactica.com.ar
The present work analyses one of the thesis for explaining the growth of government, as developed in the work Crisis and Leviathan: Critical Episodes in the Growth of American 
Government by Robert Higgs (1987). Since the author studies the application of the Ratchet Effect in the case of the US, our goal is to analyze the possibility of corroborating such a hypothesis for the case of Argentina.

First, we will present a brief exposition of the hypothesis and the analytical and methodological framework developed by Higgs. Then we will apply such hypothesis to the case of Argentina to test its soundness using the data of Public Expenditure corresponding to the years between 1961 and 2009 (Rodriguez, G. \& Borrrone F., 2012), and applying the econometric model developed by Hercowitz and Strawczynski (2004) in their work "Cyclical Ratcheting in Government Spending". Finally, we will conclude with some final remarks.

\section{THEORETICAL FRAMEWORK OF THE RATCHET EFFECT IN HIGGS (1987)}

Higgs (1987) begins his analysis by presenting a brief exposition of methodological criteria and several approaches concerning the growth of government in general, to justify the alternative hypothesis chosen as the proper ones in explaining the growth of government in the US.

Under such analysis, the author identifies those hypotheses which are often presented as the most common causes for the growth of government. The first one is Modernization (1987, 6-10), being this one a core cause since when the economy becomes more complex concerning production and exchanges, the function of delimiting property rights tends to become in turn more complex. This is why government intervention is presented as necessary, as to provide a solution to the problems derived of the delimitation of property rights, and also as an agent that could promote the internalization of negative externalities which, in the absence of the state, would be allegedly

\footnotetext{
${ }^{1}$ Note that in this case the reason provided is a negative one, without a proper analysis of whether the government could, in efficiency and efficacy, replace the action of the market.

2 On this regard, even Paul Samuelson (1969 (1991), 502), said: "Thus, consider what I have given in this paper as the definition of a public good, and what I might better have insisted upon as a definition in my first and subsequent papers: 'A public good is one that enters two or more persons' utility.' What are we left? Two
}

imposed by the market to those agents that do not enjoy the benefits which created such externalities in the first place (thus promoting inefficiencies and disequilibrium)

Higgs then remarks about the existence of Public Goods (1987, 10-11). The author says that the ambiguity in their definition is the main cause that allows and even promotes its expansion because the principles of "non-excludable" and "non-rivalry" carry by themselves such conceptual vagueness that it is difficult to concretize their application to specific goods and services. Thus, it could be said that such definition could end up applying to every conceivable good or service which is identified by an observer as one which "the market does not provide efficiently" ${ }^{\prime 2}$. Therefore, the road to government expansion is opened always that new necessities are identified to be currently dissatisfied by inexistent Public Goods (which, in turn, "have" to be created).

The Welfare State $(1987,11-12)$, also becomes relevant among the hypothesis analyzed. Its origin could be traced to certain policies of the government in Prussia during the 19th century, but its application was widespread for western countries after WWII. Although the provision of goods and services ${ }^{3}$ by the government, which translates into "welfare" for the population, is the main goal of such conception, its moral, philosophical and legal justification is based on the concept of "Second Generation Rights". A big hypostasized concept, "Society" represented by the government, is now in charge of their provision. To this, we must add that the spectacular growth of economies has generated affluence of goods and services which has created in the population a sort of anxiety of progress which in turn promotes them to demand the government the provision of such goods and services considered as "basic". In other words,

poles and a continuum in between? No. With a knifeedge pole of the private-good case and with all the rest of the world in the public-good domain by virtue of involving some 'consumption externality'."

${ }^{3}$ One of the economic effects of progress - from the perspective of the tool of the price elasticity of demand - is that at first the new good and services tend to be considered as a luxury, and as such of high elasticity, but when their use is generalized, they are considered indispensable, i.e. low elasticity. 
while new goods and services are created in a growing economy, they tend to constitute and be identified as "essential", which is why the government is demanded to provide them. These goods and services change and increase in time at the same pace as technology and knowledge. Thus, the Welfare State is not to be conceived as a provider of fixed goods and services, but rather necessarily in expansion due to the very nature of human progress as such.

Higgs also pays attention to the so-called Political Redistribution (1987, 12-15), not only concerning the provision of goods and services by itself but also regarding the conception of the idea itself. The government is considered, in this approach, as an entity that must provide "Social Justice", by providing a "fair distribution of rent". The origin of this idea could be traced in the egalitarian ideologies as well as the mistaken dichotomy Production-Distribution as developed by John Stuart Mill. This is so because this last gives a theoretical basis for the distinction between production and distribution, this establishing a conceptual difference between both processes, which in turn presents them as not necessarily correlated nor connected. This is what gives legitimacy to the idea that government intervention provides a more "fair distribution", being "fair" the criteria of the bureaucrat now. Redistribution has, necessarily and always political criteria, because the market would have had other outcomes (otherwise redistribution becomes irrelevant).

Another reason identified by the author, which would be studied in detail later, is Ideology (1987, 15-17). It mainly consists of the climate of ideas which will later promote some or every cause for government growth (or, of course, its retrenchment).

Finally, the author concentrates on the concept of Crisis (1987, 17-18) as one of the essential reasons for government growth (in fact, the second most relevant after Ideology). Once a crisis appears, is this due to war or economic crack (bust phase of the business cycle), the prevailing climate of ideas collapses for it is incapable of explaining what is happening or its possible solutions, and thus it is viewed as mistaken by the population. Then, people have no other choice (except that new ideas are presented) but to reject these and adopt new ideas to find alternatives to solve the present crisis. More specifically, people demand from the government to "do something" to overcome the situation, and therefore the government expands as a result. The key to the analysis is that, once the crisis passes, the government contracts its scope, but not in the same proportion as its expansion after the crisis. Thus, the state grows as a new crisis appears throughout time by a process of expansion and later contraction, non-proportional to the initial expansion. This phenomenon is defined as the Ratchet Effect.

The author explains that, although we may isolate more relevant causes in the growth of government, this is not a mono-causal phenomenon (1987, 18-19).

Because ideology is the main factor in the explanation of such growth, we take the definition that the author makes of the concept:

"By ideology, I shall mean a somewhat coherent, rather comprehensive belief system about social relations. To say that it is somewhat coherent implies that its components hang together, though not necessarily in a way that would satisfy a logician. To say that it is rather comprehensive implies that it subsumes a wide variety of social categories and their interrelations. Notwithstanding its extensive scope, it tends to revolve about only a few central values-for instance, individual freedom, social equality, or national glory.

Ideology has four distinct aspects: cognitive, affective, programmatic, and solidary. It structures a person's perceptions and predetermines his understandings of the social world, expressing these cognitions in characteristic symbols; it tells him whether what he 'sees' is good or bad or morally neutral, and it propels him to act following his cognitions and evaluations as a committed member of a political group in pursuit of definite social objectives. Ideologies perform an important psychological service because without them people cannot know, assess, and respond to much of the vast world of social relations. Ideology simplifies a reality too huge and complicated to be comprehended, evaluated, and dealt with in any purely factual, scientific, or another disinterested way." (1987, 37-38).

Thus, four aspects of ideology are presented: Cognitive, Affective, Programmatic and Solidary. 
Cognitive because it becomes into a conceptual structure by which the individual identifies the concretes in the world and acts accordingly; Affective because it has emotions associated with such identifications based on his concepts and the ethics derived of them, which in turn promotes its acceptance or rejection of the facts which presents to him; Programmatic because of the aforementioned actions which derive of it; and Solidary because relationships are generated with those who share the same or similar ideas.

To apply it and illustrate the implications of ideology among individuals, the author makes use of a neoclassical tool, the utility function, being ideology an essential part of the explanation of why the individual gains satisfaction or dissatisfaction from his actions. The utility function (i.e., the utility which the individual receives by consuming C's, goods and services which he acquires in the market) must be re-defined in the following manner $(1987,43)$ :

$$
U=f\left(C_{1}, C_{2}, C_{3}, \ldots, C_{n}, I\right)
$$

Being I the level of identification of the individual with the ideas which derive from the group to which he is part of, being for mere chance or voluntary acceptance, thus conditioning the utility reported by the goods and services consumed.

Under this approach, it is pointed out that the political discourse tends to influence decisively the climate of ideas, mainly through the usage of certain words or phrases, which pertain to certain relevant concepts to promote the acceptance of certain ideas (1987, 48-52). For this, the author distinguishes Universalistic Flag Words from Discriminating Flag Words, being the first of universal acceptance by antagonistic ideologies (e.g. both libertarians and communists use terms such as "Freedom"), and the second, deriving different meaning concerning the ideas of the listener (such as "Private Property"). Thus, political discourse influences the transmission of ideas using keywords or phrases such as "from each according to his ability, to each according to his needs". Language, this, is a relevant factor in the climate of ideas, and therefore of its transformation.

The reasons for the Ratchet Effect could be summarized (chronologically) in the following order (1987, 57-74):
1. The change of ideas logically before the change in the government (because if there is no idea of change, there is nothing to change to).

2. The citizens demand the political class to "do something" during the crisis.

3. Pressure Groups work to perpetuate the privileges they obtained during the crisis, whether they are private (Lobbies, Unions or Entrepreneur Associations, etc.) or Public (Public workers, program directors, etc.)

4. The taxes which increased during the crisis tend to perpetuate later, thus increasing the scope of action of the government to act and keep its expansion; without any reason to reduce its size.

5. The crisis affects how people view reality and their ideas for the role of government.

6. Government actions hide the costs of its interventions and dilute the payment among the citizens in a way such that it cannot be easily identified who are the net payers and net receivers of the benefits. Nor it is easily identifiable what are the costs and benefits of its actions. Thus, those who are damaged for these actions not necessarily identify so. On the other hand, those who benefit from this tend to promote the continuation of government expansion, i.e. its new size.

7. Ideological change reaffirms itself and tends to mold "public opinion".

In this context, and under this analytical framework, the necessary elements of study to understand and comprehend government growth are $(1987,74)$ :

"(1) socioeconomic and political conditions before, during, and after the crisis; (2) prevailing ideologies before, during, and after the crisis; (3) leading persons and elites and the interest groups they favor or represent; (4) emergency legislation and executive orders; (5) emergency agencies and their leadership; (6) operation of and reaction to the emergency measures; (7) court challenges, resulting decisions, and innovations of legal especially constitutional-doctrines; and (8) institutional legacies and perceived 'lessons' of the episode."

To illustrate the concept of the Ratchet Effect, we reproduce the schematic figure made by the author ${ }^{4}$ :

\footnotetext{
${ }^{4}$ Republished with permission by Robert Higgs.
} 


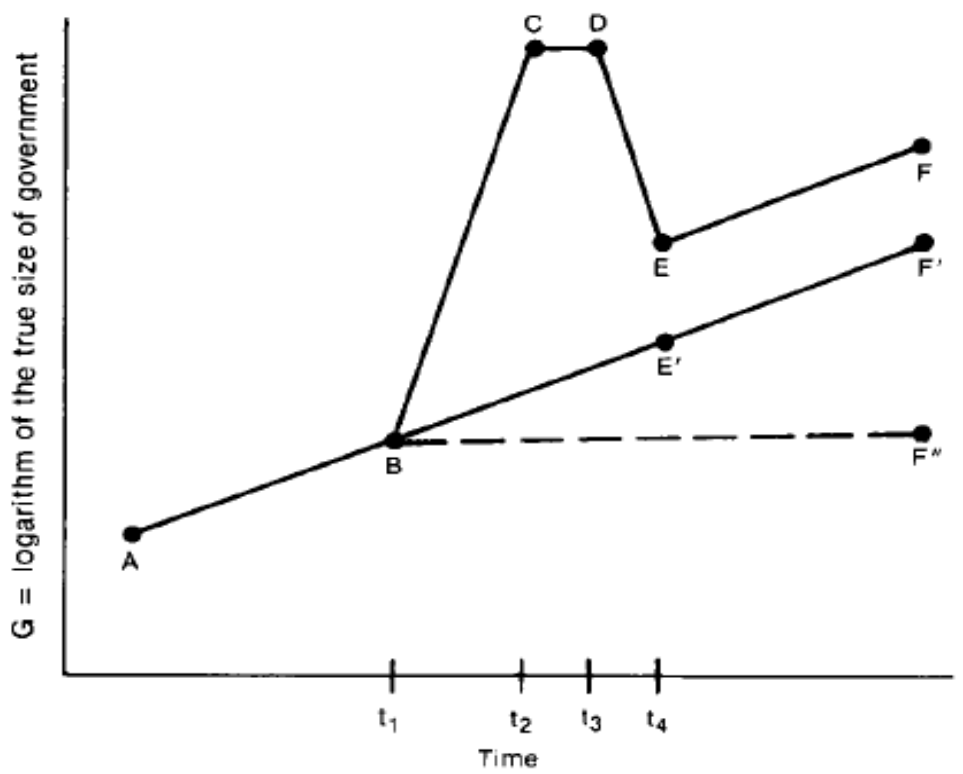

Figure 1 Schematic representation of the Ratchet (Higgs, 1987, 60)

This figure represents an episode in the growth of government where it is showed what the author defines as the Ratchet Effect. Thus, we can say the scheme consists of five steps (Higgs, 1985; 1987, 60-1):

1. Pre-crisis normality (segment $A B$ ): it is characterized by a constant rate in the growth of government (positive by the author's assumptions).

2. Expansion (segment BC): a sudden increase in the growth of government appears, created by an acceleration in the rate of growth.

3. Maturity (segment CD): in general, it is a stage where government growth does not change.

4. Retrenchment (segment DE): Government size decreases (at the same rate as the one registered during the expansion, for the assumptions of the author) but to a higher level than the one that could be achieved if the rate registered during normalcy would have been obtained (counterfactual segment AF'); thus retrenchment is "incomplete".

5. Post-crisis normalcy (segment EF): The government again grows at a rate of pre-crisis, which is why the size does not converge to the level that would have been attained if there would not have been a crisis (counterfactual point $F^{\prime}$ ).

The author concludes that in the US the growth of government appears in the context of successive crises, during which the traditional ideology (free markets, small government, etc.) changes for interventionism, to retrench later, less than proportional to the pre-crisis state. This is a key point since ideology does not change before the crisis, but because of it, and it later comes back to the traditional, but modified to a higher degree of interventionism.

Considering the intention of making an integral analysis, and not merely quantitative, the author complements his statistical information with data and elements of qualitative character. In this context, the author points out that "The ratchet applies not only to many aspects of governmental growth as measured by standard quantitative indexes; even more importantly it applies to the essence of the emergence of Big Government, the rise of government's coercive power over economic life." (1987, 33).

Next, the analysis is focused on the methodological question of how to measure the growth of government (1987, 20-34). As such, the measures will depend on the variables which are considered. We may analyze such growth based on government purchases of goods and services as a percentage of GNP, Public Expenditure as a percentage of GNP, Public workers concerning the economically active population, analysis in the growth of regulations, laws, ministries, etc.

In this respect, Higgs $(1985,3)$ tells us that:

"In my forthcoming book (Chap. 2), I have shown that several commonly employed indexes of the size of government display the 'ratchet phenomenon' during the $20^{\text {th }}$ century: government grew suddenly much bigger with the onset of each 
great crisis; after the crisis, it receded but usually not to the pre-crisis level nor even to a level that would have been reached had the pre-crisis rate of growth persisted instead of being displaced by the events of the crisis. Thus, crisis typically has produced not just a temporarily bigger government but also the permanently bigger government, according to several conventional measures. Further, we have good reason to believe, as documented in my book, that a more informative measure of government, which ideally would gauge the scope of government's effective authority over economic decision-making, would also show this ratchet phenomenon. Henceforth, I shall simply take for granted that this has been the characteristic shape of the true time profile of the growth of government in the United States in the 20th century" (emphasis added by present authors).

Therefore, in the author's analysis statistical information is complemented with elements and data of qualitative character to increase the application of the Ratchet Effect theory.

\section{METHODOLOGICAL CLARIFICATIONS}

Due to the difficulty at the time of analyzing qualitative and quantitative data together, by trying to perform comparative analysis through indexes or series, we have decided to use only quantitative data. This is so because the analysis by Higgs goes beyond the data that could be provided by, e.g. the indexes of economic freedom, which precisely use quantitative proxies to analyze specific qualitative data to test their economic impact (such indexes have been compiled by methodological apriorists such as Walter Block $(2006 ; 1991)^{5}$ at the Fraser Institute, as by mainstream economists). Given that Higgs' analysis includes social, legal and political factors, we have decided that we would not make this sort of analysis for the case of Argentina, given that we could not find a proper methodology to combine and weigh both classes of data.

In this respect, we must also make clear that the Ratchet Effect hypothesis, since it is not derived by an axiomatic deductive system such as praxeology, is a hypothesis that could be tested by empirical testing. Using the concepts developed by Ludwig Von Mises (1949 [1996]), this hypothesis is Theory to interpret History (Mises, 1957 [2007]), but since it is not derived a priori, we could not say that it must be necessarily true. In this context, the qualitative analysis which would complement the quantitative analysis is nothing more than Verstehen (understanding), for which we have decided to limit the scope of our analysis to test the hypothesis in quantitative terms.

Thus, the only way of making a quantitative analysis in this regard, of an econometric nature, is to analyze the series of Income and Public Expenditure (among others), homogenized by specific treatments.

\section{THE SELECTED MODEL}

To test Higgs' hypothesis for the case of Argentina, we based our analysis in the model presented by Hercowitz and Strawczynski (2004) in "Cyclical Ratcheting in Government Spending".

In this work, the authors try to corroborate the Ratchet Effect in the countries of the OECD. To achieve this, they use a data panel model which considers long-range considerations, as well as cyclical considerations, in the determination of public spending. Using this model, it could be determined the existence of increases in the relation expenditure/GDP, as a result of an asymmetric behavior - a "Ratchet Effect". According to the findings of the authors, the model presents evidence of the existence of an increase in the ratio of public expenditure to GDP ("size of government"), for the OECD countries during the period 1974-1998. This is partially explained by a cyclical ratchet effect with an accumulated effect of $2 \%$ of GDP $(2001,352)$. Let us now present the model.

The dynamics in government expenditure is determined by cyclical and basic considerations.

Basic considerations:

$\mathrm{g}_{\mathrm{t}}=\mathrm{g}_{\mathrm{t}} / \mathrm{y}_{\mathrm{t}}$ is the ratio of Government Expenditure $\left(\mathrm{g}_{\mathrm{t}}\right)$ and GDP $\left(\mathrm{y}_{\mathrm{t}}\right)$, which in turn represents government growth.

Thus, the dynamics in the growth of government is presented as:

\footnotetext{
${ }^{5}$ See also Easton \& Walker (1992).
} 


$$
\Delta\left(\mathrm{g}_{\mathrm{t}}\right)^{*}=\pi\left[\beta\left(\gamma-\mathrm{g}_{\mathrm{t}-1}\right)-\left(\mathrm{c}+\lg _{\mathrm{t}-1}\right)\right]
$$

$\beta\left(\gamma-g_{t-1}\right)$ represents the marginal benefit for the government, of increasing its size, and $\left(c+\omega g_{t-1}\right)$ represents the marginal cost; where $0<\pi<\infty$; and where $\beta$, $\gamma$, c y $\omega>0$.

Thus, concerning basic considerations, it is assumed that the size of the government is formed by the difference between the benefit and marginal cost. Therefore, if the marginal benefit exceeds the marginal cost in the previous period to the one understudy, the rate of growth increases. In the opposite case, if marginal benefit is below marginal cost, the rate of growth decreases.

Cyclical considerations:

It is defined

$$
\begin{aligned}
& \left(\Delta \mathrm{y}_{\mathrm{t}}\right)^{\mathrm{p}} \equiv\left(\Delta \mathrm{y}_{\mathrm{t}}-\overline{\Delta y}\right) \mathrm{d}_{\mathrm{t}} \\
& \left(\Delta \mathrm{y}_{\mathrm{t}}\right)^{\mathrm{n}} \equiv\left(\Delta \mathrm{y}_{\mathrm{t}}-\overline{\Delta y}\right)\left(1-\mathrm{d}_{\mathrm{t}}\right)
\end{aligned}
$$

where $\overline{\Delta y}$ is the rate of average growth.

$$
\mathrm{D}_{\mathrm{t}}=\left\{1 \text { if } \Delta \mathrm{y}_{\mathrm{t}} \geq \overline{\Delta y} ; 0 \text { if } \Delta \mathrm{y}_{\mathrm{t}}<\overline{\Delta y}\right\}
$$

From the variables previously defined and through the following equation,

$$
\left(\Delta \mathrm{g}_{\mathrm{t}}\right)^{\mathrm{c}}=\alpha_{1}\left(\Delta \mathrm{y}_{\mathrm{t}}\right)^{\mathrm{p}}+\alpha_{2}\left(\Delta \mathrm{y}_{\mathrm{t}}\right)^{\mathrm{n}}
$$

it is expressed the behavior of cyclical expenditure, where coefficients $\alpha_{1}$ and $\alpha_{2}$, capture the pattern of expenditure under expansion and retrenchment, respectively.

In this context, the following behaviors could be presented: symmetric and asymmetric.

In symmetric behavior, the rate of growth has the same effect in periods of expansion and retrenchment, the case where $\alpha_{1}$ and $\alpha_{2}$ equal $\alpha$. When $\alpha$ is zero, there is no relation between the rate of growth and the cycle.

And if $\alpha$ is positive the rate of growth increases during expansion and decreases during contraction, giving rise to a pro-cyclical effect. The opposite case appears when $\alpha$ is negative, being in the presence of a counter-cyclical case.

Under asymmetrical behavior, the effect of expansion is different from that of retrenchment, which could come, for example, from the application Keynesian policies, and indicate a
Ratchet Effect. In this situation, it is presented the case where $\alpha_{1}>\alpha_{2}$.

To summarize, we have the following cyclical patterns:

a) Symmetrical behavior:

$\alpha_{1}=\alpha_{2}=\alpha \rightarrow$ the same behavior during expansion and retrenchment.

If $\alpha=0 \rightarrow$ no relation between the cycle and $\boldsymbol{g}$

If $\alpha>0 \rightarrow \boldsymbol{g}$ is pro-cyclical, or

if $\alpha<0 \rightarrow \boldsymbol{g}$ is counter-cyclical.

b) Asymmetrical behavior:

If $\alpha_{1}>\alpha_{2} \rightarrow \boldsymbol{g}$ increases through time.

Through a regression equation, it is defined as the rate of government growth in which are considered as explanatory variables both the cyclical and basic behaviors.

Considering both basic and cyclical aspects, $\boldsymbol{g}$ is modeled by the regression equation:

$$
\begin{aligned}
\Delta \mathrm{g}_{\mathrm{t}}= & \left(\Delta \mathrm{g}_{\mathrm{t}}\right)^{*}+\left(\Delta \mathrm{g}_{\mathrm{t}}\right)^{\mathrm{c}}+\mathrm{e}_{\mathrm{t}}= \\
& =\alpha_{0}+\alpha_{1}\left(\Delta \mathrm{y}_{\mathrm{t}}\right)^{p}+\alpha_{2}\left(\Delta \mathrm{y}_{\mathrm{t}}\right)^{\mathrm{n}}+\lambda \mathrm{g}_{\mathrm{t}-1}+\varepsilon_{\mathrm{t}}
\end{aligned}
$$

where $\alpha_{0}=\pi(\beta \lambda-c), \lambda=-\pi(\beta+\omega)$ and $\varepsilon_{t}$ is white noise.

\section{APPLICATION TO THE CASE OF ARGENTINA}

In this section we make a study of the possible application of the hypothesis of the Ratchet Effect to the case of Argentina. For this goal we make use of the data series developed by Rodriguez and Borrrone (2012) in "La política fiscal en la Argentina y su relación con el ciclo económico: evolución de las cuentas públicas presupuestarias y del producto bruto interno para el período 19612009. Based on these series of current expenditure, total expenditure, and GDP we can make the following observations (Fig. 2).

The size of government as measured by the ratio TE/GDP registers a fall between 1961 and 1965 from $25.99 \%$ to $22.03 \%$ due to a growth rate of GDP above the growth rate of TE. Later, between 1966 and 1974 there is an increase in the size of government, getting to $29.42 \%$. This is due to the increase in TE, in the years 1973 and 1974 as well, when rates of $20 \%$ and $28 \%$ were registered, respectively, with an increase in GDP of $9.66 \%$ and $10.12 \%$, respectively. For 1977 , we note a fall to $23.58 \%$ due to positive rates of product growth along with a fall in the rate of total expenditure. 
From this year on, we could say that growth in government begins until the year 1981 when it reaches a point of $30.92 \%$. This is caused by the fact that total expenditure increases above the product in such a period, and even in 1981, where GDP falls by $6.47 \%$, total expenditure increases by $2.6 \%$. If we observe the period 1981-1991, we see a tendency towards a decline in the size of the government, from the prior $30.92 \%$ to $22.10 \%$ in 1991. This fall was caused by an increase in GDP and a fall in TE.

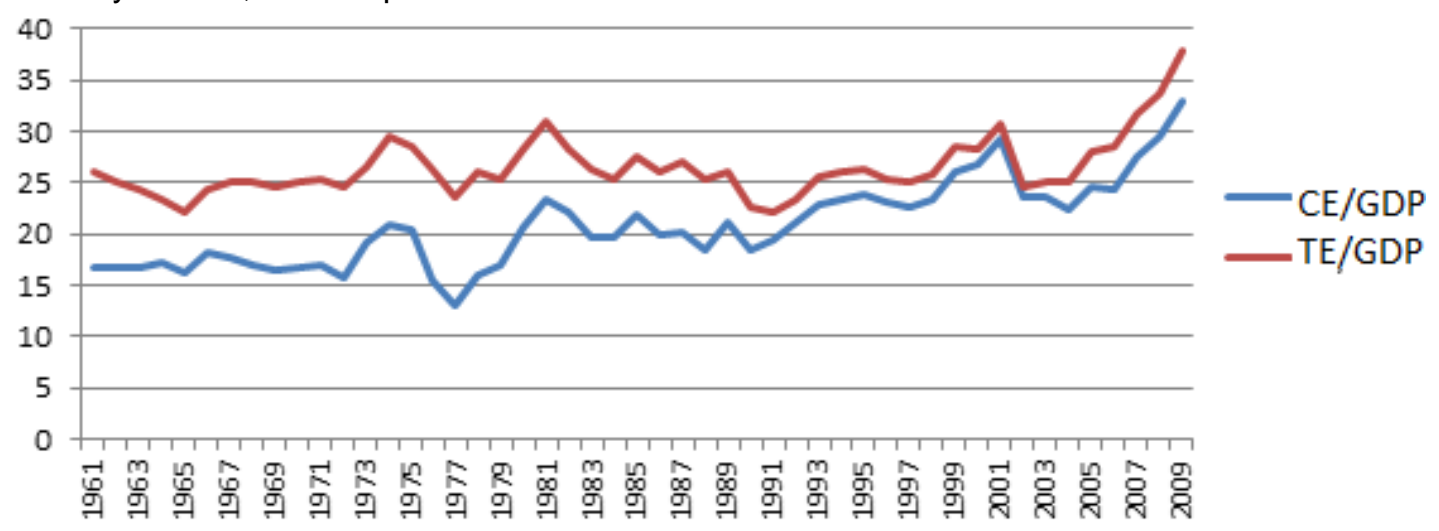

Figure 2 Total Expenditure/GDP and Current Expenditure/GDP in percentages - Constant prices of 2009 Source: Authors based on data of Rodriguez and Borrone (2012)

In the period 1991-2001, we observe that the size of government increases from $22.10 \%$ to $30.64 \%$. In the year 2002, a big fall in the size of the government is registered, to $24.6 \%$ due to an even bigger fall in total expenditure by $38.34 \%$, than that of GDP which was $10.9 \%$. From this point on the size of government always increases until getting to a high of $37.62 \%$ in 2009 . This happens because of an increase in total expenditure above the increase in the rate of growth of GDP (from 2004 on).

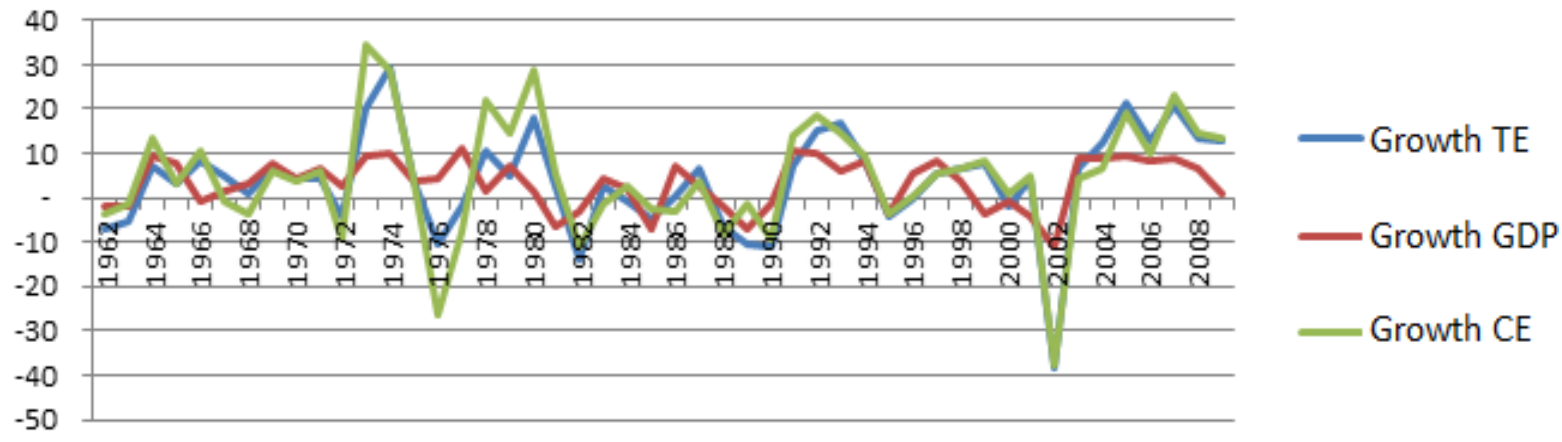

Figure 3 Rates of growth of GDP, current expenditure, and total expenditure - constant prices of 2009 Source: Authors based on data of Rodriguez and Borrone (2012)

Before a deeper analysis by the application of econometric tools, we can observe that the hypothesis of the Ratchet Effect is not corroborated in the case of Argentina for the period 1961-2009. Further, the ratio of public expenditure to GDP is always between two points with an approximate low of $20 \%$ and an approximate high of $30 \%$.

Thus, to evaluate the ratchet effect under an econometric analysis, we make use of the aforementioned equation (in section 4), taking into account the official data on total expenditure and GDP.
There we take as a variable of study the increase in the ratio total expenditure to GDP and as explanatory variables those which indicate the periods of expansion and retrenchment, and the previous period total expenditure/GDP ratio.

Such analysis gave us results presented in Table 1.

Thus, according to the presented model, we can conclude with a significant level of $5 \%$, that there is no significate effect to GDP in periods of expansion (a positive increase of GDP), in periods of retrenchment (a negative increase of GDP), as 
well as the increase in the differentiated ratio total expenditure/GDP. In other words, there is no relation between the differentiation in the ratio total expenditure/GDP and the differentiated GDP in expansion, nor for the differentiated GDP in contraction. Also, the ratio expenditure/GDP in a period does not depend on the previous one (see the column of $p$-value in the Parameter Estimation table).

Table 1Parameter Estimation
\begin{tabular}{|l|r|r|}
\hline Parameter & $\begin{array}{l}\text { Estimated } \\
\text { Value }\end{array}$ & \multicolumn{1}{c|}{ P-value } \\
\hline$\alpha_{0}$ & 0.139 & $0.008^{*}$ \\
\hline$\alpha_{1}$ & $-3.5^{*} \mathrm{E}-13$ & 0.199 \\
\hline$\alpha_{2}$ & $3.23^{*} \mathrm{E}-13$ & $0.095^{* *}$ \\
\hline$\wedge$ & -0.404 & $0.009^{*}$ \\
\hline
\end{tabular}
Notes:
* significant at 5\%; ** significant at $10 \%$.

To a significant level of $10 \%$, the GDP in periods of contraction turns significate, for which it is related to the differentiation of the ratio total expenditure/GDP ( $p$-value $=0.0910)$.

The conclusions of the model are valid because its assumptions take place, i.e. Independence, constant variance, and normal distribution of residuals (see ANNEX A). Also, there is no multicollinearity among the explanatory variables.

\section{CONCLUSION}

Based on the previous quantitative analysis, we were not able to find insights that prove the existence of a cyclical ratchet effect in Argentina. Thus, the case of this country does not provide evidence of an asymmetric fiscal behavior which gives rise to an expansion in the ratio public expenditure/GDP during the bust phases of the business cycle, followed by retrenchments at a rate less than proportional to the increase phases. Therefore, we can say that the hypothesis of Higgs, tested using the model of Hercowitz and Strawczynski, cannot be applied to the case of Argentina for the period 1961-2009.

Finally, we would like to remark that our results do not invalidate the possibility of the existence of a specific dynamic in the growth of Argentina's government compatible with Higgs hypothesis based on qualitative data. So, the doors are still open for future research applying qualitative analysis in this regard.

\section{WORKS CITED}

Block, W. (2006). Paul Craig Roberts on empirical measures of economic freedom: a rejoinder. International Journal of Social Economics, Vol. 33 No. 7, pp. 481-490.

Block, W (ed.). (1991). Economic Freedom: Toward a Theory of Measurement. Proceedings of an International Symposium on Measuring Economic Freedom held July 28-30, 1988, in Vancouver, British Columbia. The Fraser Institute: Vancouver.

Easton, S. T. \& Walker, M. A. (eds.). (1992). Rating Global Economic Freedom. The Fraser Institute: Vancouver.

Higgs, R. (1985, Jan.). Crisis, bigger government, and ideological change: two hypotheses on the ratchet phenomenon. Explorations in Economic History, 22, pp. 1-28.

Higgs, R. (1987). Crisis and Leviathan: Critical Episodes in the Growth of American Government. Oxford University Press: New York.

Hercowitz, Z., \& Strawczynski, M. (2004). Cyclical Ratcheting in Government Spending: Evidence from the OECD. The Review of Economics and Statistics, 86(1) (Feb. 2004), pp. 353-361.

Mises, Ludwig V. 1949 (1996). "Human Action: A Treatise on Economics". San Francisco: Fox \& Winkles.

Mises, Ludwig V. 1957 (2007). "Theory and History”. Ludwig Von Mises Institute: Auburn.

Rodriguez, G., \& Borrrone, F. (2012, Nov). La política fiscal en la Argentina y su relación con el ciclo económico: evolución de las cuentas públicas presupuestarias y del producto bruto interno 
para el período 1961-2009. Anales. Asociación Argentina de Economía Política. http://www.aaep.org.ar/anales/works/works2012/Rodriguez_Borrone.pdf.

Samuelson, P. (1969). Pure Theory of Public Expenditure and Taxation. In J. Margolis, \& e. H Guitton, Public Economics: An Analysis of Public Production and Consumption and Their Relations to the Private Sectors (pp. 492-517). London: Macmillan.

\section{ANNEX A}

To corroborate that the adjusted model is correct, we made an analysis of residuals (in the following figures), which indicate that the adjustment is adequate.

Normality

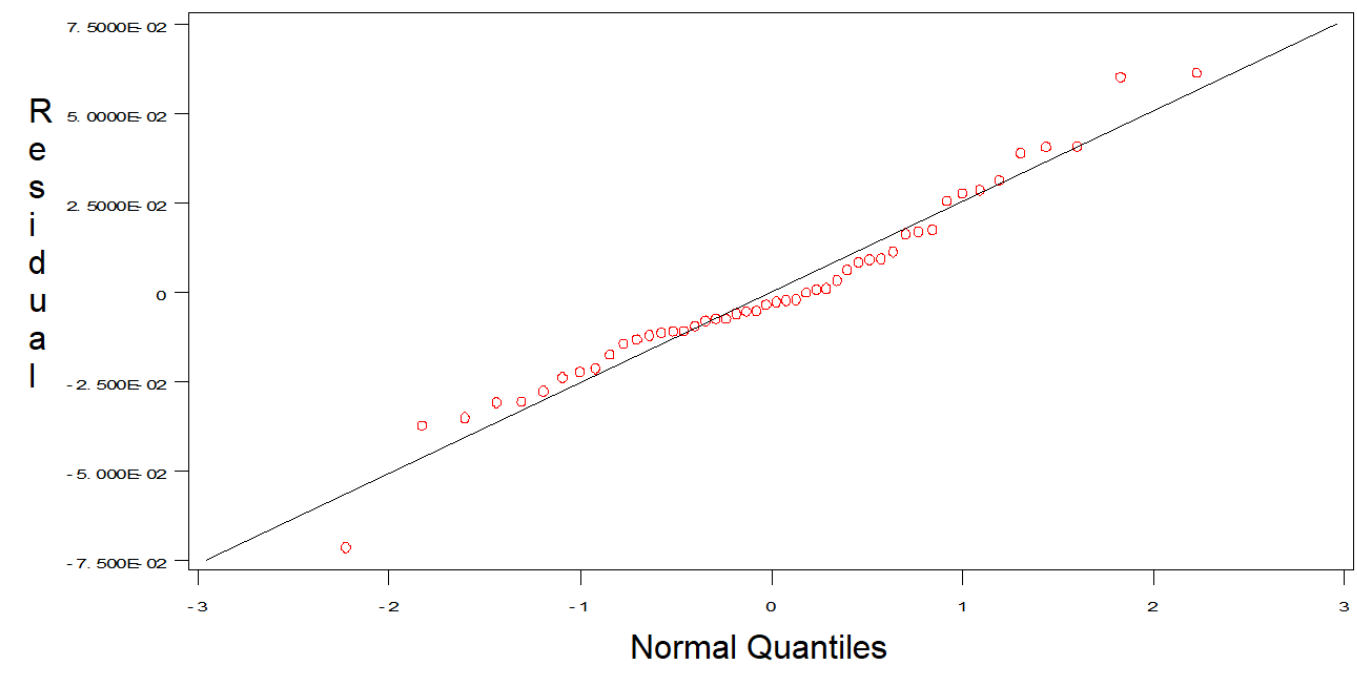

Residuals vs Predicted Values

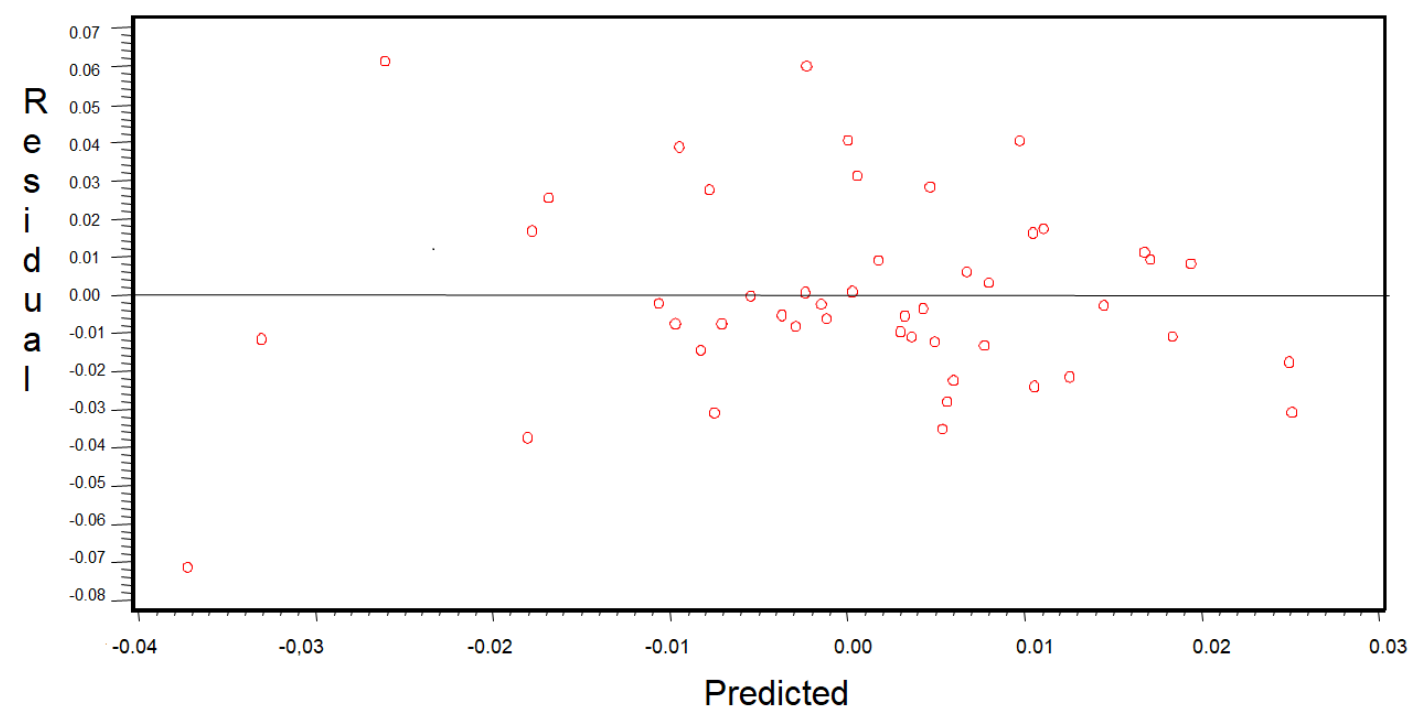




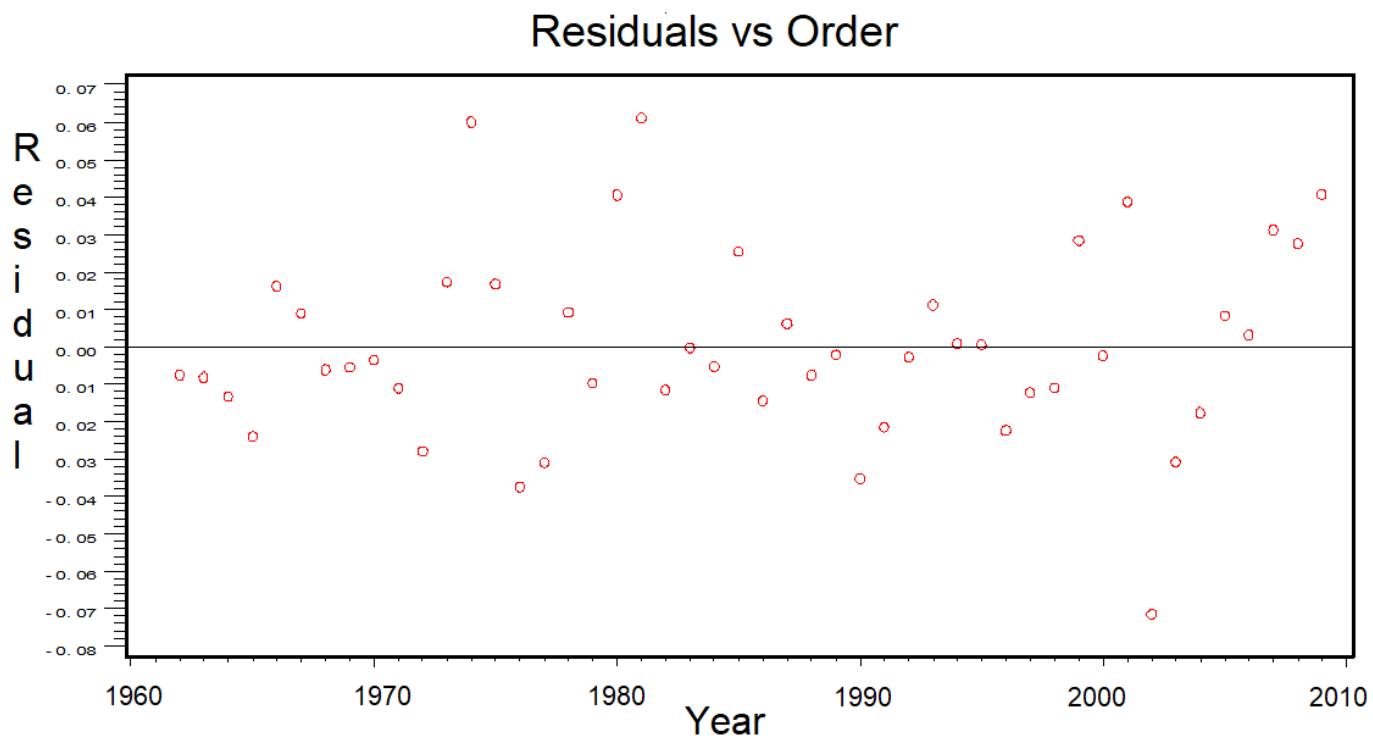

\begin{tabular}{|l|c|c|}
\hline \multicolumn{4}{|l|}{ Normality Test } \\
\hline Statistic & Value & \multicolumn{1}{l|}{$p$-value } \\
\hline Kolmogorov-Smirnov & 0.121 & 0.08 \\
\hline
\end{tabular}

\section{NOTE}

The present work was prepared in the context of the Investigations Group at Bases Foundation, and a former version of this paper was presented in the Fifth International Congress "The Austrian School in the $21^{\text {th }}$ Century", Nov. 19, 2014, Pontificia Universidad Católica Argentina UCA, Rosario, Argentina, https://www.youtube.com/watch?v=qS9aLQ1VvcU.

\section{ACKNOWLEDGMENT}

We wish to thank the collaboration of Fernanda Bonifazi (UNR - Argentina) and Cecilia Guillamet Chargue (UNR - Argentina) in the application of the econometric model (Sections II.3 and III.) of Hercowitz and Strawczynski (2004) to the case of Argentina based on the data by Rodriguez G. and Borrrone F. (2012).

Received for publication:

Revision received:

Accepted for publication:
16.02 .2020

22.04.2020

01.07 .2020

\section{How to cite this article?}

Style - APA Sixth Edition:

Tejera, A. R., Veron, L. A., \& Futerman, A. G. (2020, July 15). The "ratchet effect" in the growth of government: A viable hypothesis for the case of Argentina? (Z. Cekerevac, Ed.) MEST Journal, 8(2), 164-175. doi:10.12709/mest.08.08.02.19 
Style - Chicago Sixteenth Edition:

Tejera, Ariel R., Leandro A. Veron, and Alan G. Futerman. 2020. "The "ratchet effect" in the growth of government: A viable hypothesis for the case of Argentina?" Edited by Zoran Cekerevac. MEST Journal (MESTE) 8 (2): 164-175. doi:10.12709/mest.08.08.02.19.

Style - GOST Name Sort:

Tejera Ariel R., Veron Leandro A. and Futerman Alan G. The "ratchet effect" in the growth of government: A viable hypothesis for the case of Argentina? [Journal] // MEST Journal / ed. Cekerevac Zoran. - Belgrade - Toronto : MESTE, July 15, 2020. - 2 : Vol. 8. - pp. 164-175.

Style - Harvard Anglia:

Tejera, A. R., Veron, L. A. \& Futerman, A. G., 2020. The "ratchet effect" in the growth of government: A viable hypothesis for the case of Argentina?. MEST Journal, 15 July, 8(2), pp. 164-175.

Style - ISO 690 Numerical Reference:

The "ratchet effect" in the growth of government: A viable hypothesis for the case of Argentina? Tejera, Ariel R., Veron, Leandro A. and Futerman, Alan G. [ed.] Zoran Cekerevac. 2, Belgrade - Toronto : MESTE, July 15, 2020, MEST Journal, Vol. 8, pp. 164-175. 